\title{
Adubação nitrogenada sobre a ocorrência de doenças em pós-colheita do morango
}

\section{Effect of nitrogen doses on the occurrence of postharvest diseases in strawberry}

\author{
Ivan Herman Fischer ${ }^{1 *}$, Flávio Fernandes Júnior ${ }^{2}$, Cristiaini Kano ${ }^{3}$, Alceu Donadelli ${ }^{4}$, \\ Maria Cecília de Arruda Palharini ${ }^{1}$
}

||||||||||||||||||||||||||||||||||||||||||||||||||||||||||||||||||||||||||||||||||||||||||||||||||||||||||||||||||||||||||||||||||||||||||||||||||||||||||||||||||||||||||||||||||||||||||||||||||||||||||||||||||||||||||||||||||||||||||| |-

RESUMO: Avaliou-se o efeito de doses de nitrogênio, aplicadas em campo, sobre as doenças pós-colheita nos cultivares de morango Camino Real, Festival e Oso Grande. O nitrogênio, tendo como fonte a ureia, foi avaliado na dose recomendada total (100\%), com base na recomendação oficial para a cultura, e mais 3 doses inferiores $(83,67$ e $50 \%$ do recomendado), tanto no plantio como em cobertura. Os frutos foram colhidos e pesados com $75 \%$ da superfície de cor vermelho-brilhante. Doze frutos por parcela foram amostrados em 3 coletas a partir da segunda florada e avaliados quanto à incidência das doenças durante 5 dias de armazenamento a $25^{\circ} \mathrm{C}$ e $85 \%$ de umidade relativa. A identificação das doenças foi feita diariamente com base nos sintomas e sinais dos patógenos. Não foi observado efeito das doses de nitrogênio na produçáo de frutos e na incidência das doenças, expressa em área abaixo da curva de progresso da doença (AACPD). A maior produção foi observada nos cultivares Festival e Oso Grande. A incidência total de doenças não diferiu significativamente entre os cultivares. $\mathrm{O}$ mofo cinzento foi a principal doença, com incidência superior a $30 \%$, seguido da podridáo mole de Rhizopus e podridão de levedura.

PALAVRAS-CHAVE: adubação nitrogenada; morangueiro; podridôes; produçáo.

\begin{abstract}
This study evaluated the effect of nitrogen doses on postharvest diseases of strawberry cultivars Camino Real, Festival and Oso Grande. The nitrogen in urea formulation was evaluated at the recommended dose (100\%) based on the official recommendation to the culture, and 3 lower doses (83, 67 and 50\% of recommended), considering the fertilization at planting and cover applications. Fruits were harvested and weighed at $75 \%$ of its surface with a bright red color. Twelve fruits per plot were sampled in 3 collections from the second flowering and assessed for disease incidence during five days of storage at $25^{\circ} \mathrm{C}$ and $85 \%$ relative humidity. The identification of disease was made daily, based on symptoms and pathogen signs. There was no effect of nitrogen doses on yield and incidence of postharvest diseases, expressed as area under the disease progress curve (AUDPC). Increased average production was observed in cultivars Festival and Oso Grand. The overall incidence of disease among the cultivars did not differ significantly. Gray mold was the main disease, affecting more than $30 \%$ of fruits, followed by Rhizopus and yeast rot.
\end{abstract}

KEYWORDS: nitrogen fertilization; strawberry; rots; production. 
O morango é uma infrutescência da família das rosáceas e gênero Fragaria. A comercialização e a disponibilidade de morangos são restritas pela rápida deterioração dos frutos, causada pela senescência e doenças pós-colheita, com uma vida útil estimada em três a sete dias sob condição ambiente (Henz et al., 2008). Dentre as várias doenças que comprometem a qualidade e a quantidade do morango em pós-colheita, destacam-se a podridão mole, causada por Rhizozus nigricans Ehrenb. e Mucor spp., e o mofo cinzento, causado por Botrytis cinerea Pers. ex Fries (Cantillano; Silva, 2010).

Dentro do conceito de produção integrada, é fundamental o desenvolvimento de tecnologias que consideram as relações nutricionais com a produtividade e também com fatores fitossanitários, tais como a ocorrência das doenças. O manejo do nitrogênio é, muitas vezes, limitante e, de acordo com RaIJ (1991), enquanto adubaçóes elevadas podem proporcionar aumento na suscetibilidade das plantas a doenças, a deficiência na quantidade desse elemento pode ocasionar a redução na produtividade. A adubação nitrogenada, tanto na forma mineral quanto orgânica, promoveu a concentração desse nutriente nas folhas do morangueiro, sendo que esses teores correlacionaram-se diretamente com a severidade da antracnose do rizoma, causada por Colletotrichum fragarie (Tanaka et al., 2002). Todavia, Marschner (1995) comentou que todos os fatores que favorecem as atividades metabólicas e de síntese de células das hospedeiras, a exemplo do nitrogênio, também corroboram a resistência das plantas a algumas doenças. Assim, deve-se buscar um ponto de equilíbrio entre a adubação nitrogenada e a qualidade fitossanitária dos pomares.

A atualização das recomendaçóes de adubação para o morangueiro é tema levantado com frequência em encontros técnicos da cultura, uma vez que essas foram estabelecidas em RAIJ et al. (1996) e Ribeiro et al. (1999) para cultivares com potencial produtivo bem inferior aos utilizados atualmente. Em razáo do maior potencial produtivo dos cultivares em uso no Brasil, é senso comum entre os produtores a necessidade de aporte de doses maiores do que as preconizadas nas recomendaçóes oficiais e alteraçóes nas doses recomendadas são feitas de forma empírica. No sul de Minas e nos municípios de Atibaia e Jarinú, importante região produtora de São Paulo, a aplicação da formulaçáo de adubo 4-14-8 (N-P-K) na dosagem de 50 a 100 g por planta como adubação de base implica no aporte de 120 a $240 \mathrm{~kg} \cdot \mathrm{ha}^{-1}$ de $\mathrm{N}$ só no plantio, quando o recomendado por RAIj et al. (1996) é a aplicaçáo de 40 kg.ha-1 de N no plantio. Ribeiro et al. (1999) recomendaram $40 \%$ no plantio da dose total de $\mathrm{N}$ recomendada, que é de $220 \mathrm{~kg} \cdot \mathrm{ha}^{-1}$ de N. Dentro dessa prática aplica-se ainda 480 a 840 kg.ha- de $\mathrm{P}_{2} \mathrm{O}_{5}$ e 240 a 480 kg.ha- ${ }^{-1}$ de $\mathrm{K}_{2} \mathrm{O}$. Para o potássio, RAIJ et al. (1996) recomendaram de 100 a 400 kg.ha-1 de $\mathrm{K}_{2} \mathrm{O}$ e Ribeiro et al. (1999), de 80 a 350 kg.ha-1 de $\mathrm{K}_{2} \mathrm{O}$.

Em função da escassez de informaçóes sobre a relação entre adubação nitrogenada e ocorrência de doenças em morangueiro, objetivou-se avaliar o efeito da adubação nitrogenada sobre as doenças pós-colheita nos cultivares de morango Camino Real, Festival e Oso Grande.

O experimento foi conduzido no município de Atibaia, São Paulo (latitude sul de $23^{\circ} 07^{\prime} 01^{\prime \prime}$, longitude oeste de 46³3'01", altitude média de 803 metros e clima Cwb tropical de altitude, segundo a classificação de Köppen), em condiçóes de campo aberto de abril a dezembro de 2010 . Os canteiros foram erguidos com o auxílio de rotoencanteirador e as adubaçóes de plantio e cobertura foram realizadas mediante análise de solo, conforme as recomendaçôes oficiais do Boletim Técnico 100 (RAIJ et al., 1996), com exceção do nitrogênio $(\mathrm{N})$ empregado na recomendação oficial (100\%) e mais 3 doses inferiores (50, 67 e 83\% do recomendado), tanto no plantio como em cobertura.

$\mathrm{Na}$ adubação de plantio foram aplicados $600 \mathrm{~kg} \cdot \mathrm{ha}^{-1} \mathrm{de}$ $\mathrm{P}_{2} \mathrm{O}_{5}, 30$ toneladas de esterco de curral e $\mathrm{N}$, na forma de ureia, em 4 dosagens (20; 26,6; 33,3 ou $40 \mathrm{~kg} \cdot \mathrm{ha}^{-1}$ de N), considerando a maior dose a recomendada, náo havendo necessidade de calagem. As adubaçóes em cobertura seguiram os mesmos percentuais de $\mathrm{N}$, sendo as doses recomendadas $180 \mathrm{~kg} \cdot \mathrm{ha}^{-1}$ de $\mathrm{N}$ e $90 \mathrm{~kg} \cdot \mathrm{ha}^{-1}$ de $\mathrm{K}_{2} \mathrm{O}$. A adubação de plantio foi via sólida e as adubaçôes de cobertura divididas em seis aplicaçôes conforme recomendação (RAIJ et al., 1996), iniciadas após um mês do transplante e aplicadas via líquida ao pé de cada planta.

O delineamento experimental utilizado foi em blocos ao acaso em esquema fatorial com 3 cultivares (Camino Real, Festival e Oso Grande) e 4 doses de N, totalizando 12 tratamentos com 4 repetiçóes. Cada parcela foi composta por 15 plantas (3 linhas com 5 plantas) sendo as 9 centrais consideradas úteis.

As mudas foram transplantadas no espaçamento de $0,30 \mathrm{x}$ 0,33 m e o mulching aplicado após limpeza de folhas e primeira capina, como se faz convencionalmente. $\mathrm{O}$ sistema de irrigação até o pegamento das mudas foi por aspersão e depois dessa fase, por gotejamento. Para o manejo das doenças foi realizada no mês de julho uma pulverização com procimidone, visando ao controle de mofo cinzento, em outubro uma aplicação de azoxystrobin para controle da podridão da podridão mole, e em novembro duas aplicaçóes com azoxystrobin e dinefoconazole visando ao controle da podridão mole.

Os morangos foram colhidos e pesados quando apresentaram $75 \%$ da superfície de cor vermelho-brilhante. Doze frutos por parcela foram amostrados em três coletas a partir da segunda florada, individualizados em bandejas plásticas e avaliados diariamente quanto à incidência de doenças pós-colheita durante cinco dias de armazenamento a $25^{\circ} \mathrm{C}$ e $85 \%$ de umidade relativa (UR) em câmara frigorífica. A identificação das doenças foi feita com base nos sintomas visuais e a observação dos sinais dos patógenos, em microscópio de luz. Diagnosticada a etiologia do agente causal da podridáo, o fruto foi descartado. 
A partir dos dados de incidência de doenças foi calculada a área abaixo da curva de progresso da doença (AACPD) e as médias entre doenças nos cultivares e entre cultivares de morango foram comparadas pelo teste Tukey $(\mathrm{p}<0,05)$. Para os dados de AACPD e de produçáo de morango em $\mathrm{g}$ planta $^{-1}$, em função da dose de $\mathrm{N}$, foi empregada análise de regressão quadrática e caso significativo, comparadas pelo teste de Tukey $(\mathrm{p}<0,05)$.

Não foi observado efeito significativo da adubaçáo nitrogenada na produçáo de frutos e na incidência total das doenças pós-colheita, com média de AACPD nos cultivares de morango Camino Real, Festival e Oso Grande, de 138,6; 96,6 e 138,3, respectivamente, de modo que a redução em $50 \%$ da adubação nitrogenada em relação ao proposto pelo Boletim Técnico 100, além de propiciar redução no custo de produção, não afetou negativamente a cultura na região de Atibaia, São Paulo. Maior produção média foi observada nos cultivares Festival $(1070,5 \mathrm{~g}$ planta $\left.^{-1}\right)$ e Oso Grande $\left(940,8\right.$ g planta $\left.^{-1}\right)$ em relação à Camino Real (595,3 g planta $^{-1}$ ) (Tabela 1). Avaliando a produtividade de oito cultivares de morango em sistemas de cultivo orgânico e convencional, CAMARgo et al.
(2010) também observaram diferenças entre os cultivares em ambos os sistemas de cultivo, sendo a produtividade média do cultivar Camino Real 36,3\% inferior em relaçáo ao cultivar Oso Grande, semelhante aos 36,7\% de reduçáo observada no presente trabalho.

A incidência total de doenças entre os cultivares não diferiu significativamente durante o armazenamento (Tabela 2), entretanto, diferenças foram observadas para as três doenças mais incidentes, sendo maior a incidência da podridáo mole de Rhizopus e podridão de levedura no cultivar Oso Grande em relação aos cultivares Camino Real e Festival, e maior a incidência de mofo cinzento no cultivar Camino Real em relação ao Oso Grande.

$\mathrm{Na}$ média dos cultivares, mofo cinzento foi a principal doença, apresentando um acentuado incremento ao final do armazenamento, com incidência superior a $20 \%$ aos quatro dias de armazenamento e $30 \%$ no quinto dia (Fig. 1), seguida da podridão mole de Rhizopus e podridáo de levedura (Tabela 2), com incidência inferior a $20 \%$ ao final do armazenamento. Essa elevada incidência de doenças, superior aos $20 \%$ encontrados durante o período de armazenamento dos morangos (Paull, 1999), pode ser atribuída à alta temperatura $\left(25^{\circ} \mathrm{C}\right) \mathrm{e}$

Tabela 1. Produção (g planta-1) de cultivares de morangos submetidos a diferentes doses de nitrogênio na forma de ureia, no plantio e em cobertura. Atibaia, São Paulo, 2010.

\begin{tabular}{|c|c|c|c|c|}
\hline Doses de nitrogênio (kg.ha-1) & & & & \\
\hline (plantio - cobertura) & Oso Grande & Festival & Camino Real & Média \\
\hline $20,0-90,0$ & $952,1 \mathrm{aA}^{1}$ & 1117,3 aA & $579,5 \mathrm{bA}$ & $883,0 \mathrm{~A}$ \\
\hline $26,6-120,6$ & 882,8 aA & $1074,2 \mathrm{aA}$ & $611,6 \mathrm{bA}$ & $856,2 \mathrm{~A}$ \\
\hline $33,3-149,4$ & 974,8 aA & $1013,7 \mathrm{aA}$ & $565,0 \mathrm{bA}$ & $851,2 \mathrm{~A}$ \\
\hline $40,0-180,0$ & $953,3 \mathrm{aA}$ & $1076,8 \mathrm{aA}$ & $625,1 \mathrm{bA}$ & $885,1 \mathrm{~A}$ \\
\hline Média & $940,8 \mathrm{a}$ & $1070,5 \mathrm{a}$ & $595,3 b$ & \\
\hline CV (\%) & & & & \\
\hline
\end{tabular}

'Valores seguidos pela mesma letra, minúscula na linha e maiúscula na coluna, não diferem entre si, em nível de $5 \%$ pelo teste de Tukey ao nível $5 \%$ de significância. CV = coeficiente de variação.

Tabela 2. Área abaixo da curva do progresso da incidência de doenças pós-colheita em cultivares de morango, durante cinco dias de armazenamento a $25^{\circ} \mathrm{C}$ e $85 \%$ de umidade relativa.

\begin{tabular}{|c|c|c|c|c|}
\hline \multirow{2}{*}{ Doenças } & \multicolumn{4}{|c|}{ Cultivares } \\
\hline & Oso Grande & Festival & Camino Real & Média \\
\hline Mofo cinzento & $33,4 \mathrm{bA}^{1}$ & $53,6 \mathrm{abA}$ & $76,1 \mathrm{aA}$ & $54,4 \mathrm{~A}$ \\
\hline Podridão mole de Rhizopus & 56,8 aA & $19,1 \mathrm{bB}$ & $20,5 \mathrm{bB}$ & $30,8 \mathrm{~B}$ \\
\hline Podridão de levedura & $29,2 \mathrm{aAB}$ & $8,0 \mathrm{bBC}$ & $16,5 \mathrm{bBC}$ & $17,6 \mathrm{BC}$ \\
\hline Antracnose & $9,6 \mathrm{aBC}$ & $3,8 \mathrm{aBC}$ & $15,7 \mathrm{aBC}$ & $9,7 \mathrm{C}$ \\
\hline Podridão de Pestalotiopsis & $2,0 \mathrm{aC}$ & $10,3 \mathrm{aBC}$ & $13,8 \mathrm{aBC}$ & $8,7 \mathrm{CD}$ \\
\hline Podridão de Cladosporium & $2,0 \mathrm{aC}$ & $1,4 \mathrm{aC}$ & $1,7 \mathrm{aCD}$ & $1,7 \mathrm{DE}$ \\
\hline Podridão de Phytophthora & $4,5 \mathrm{aC}$ & $0,0 \mathrm{aC}$ & $0,0 \mathrm{aD}$ & $1,5 \mathrm{E}$ \\
\hline Podridão de Penicillium & $0,5 \mathrm{aC}$ & $0,5 \mathrm{aC}$ & $0,0 \mathrm{aD}$ & $0,3 \mathrm{E}$ \\
\hline Total & 138,0 a & 96,6 a & 138,6 a & 124,6 \\
\hline CV (\%) & \multicolumn{4}{|c|}{30,2} \\
\hline
\end{tabular}

'Valores seguidos pela mesma letra, minúscula na linha e maiúscula na coluna, não diferem entre si, em nível de $5 \%$ pelo teste de Tukey ao nível $5 \%$ de significância. Análise estatística com os dados transformados em $\sqrt{ } x+0,5$. CV = coeficiente de variação. 


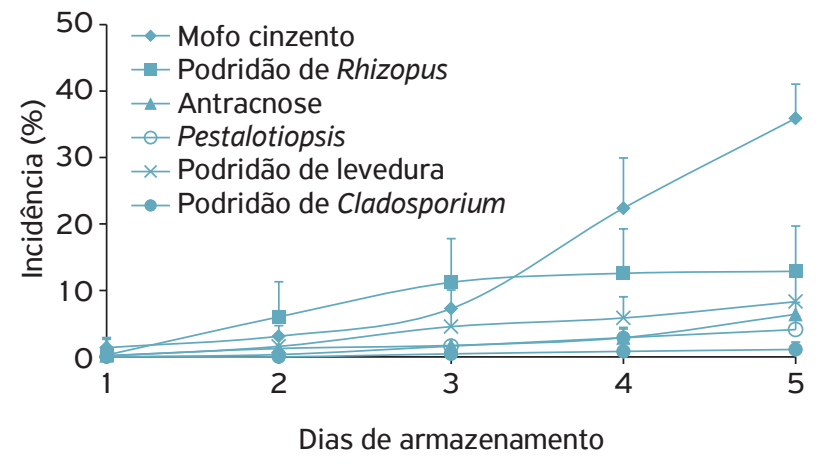

As barras representam o erro padrão da média.

Figura 1. Incidência média de doenças pós-colheita de três cultivares (Oso Grande, Festival e Camino Real) de morango durante cinco dias de armazenamento a $25^{\circ} \mathrm{C}$ e $85 \%$ de umidade relativa.

umidade (85\% UR) de armazenamento, favoráveis ao desenvolvimento dos patógenos (Bendo; VIeCELLI, 2009), e fatores de campo e práticas culturais, como também relatado por WANG et al. (2014). Danos pelo mofo cinzento em pós-colheita podem chegar a 20 a $40 \%$ em poucos dias (BRACKMANn et al., 2001), tornando-se um dos maiores entraves da cultura por limitar a comercialização, sobretudo a grandes distâncias. Em levantamento realizado no Distrito Federal, a podridáo mole foi a doença mais incidente, entre 21 e $98 \%$, seguida pela podridáo de levedura, entre 8 e $44 \%$, enquanto o mofo cinzento não foi constatado, possivelmente relacionado à baixa UR no período (Henz et al., 2008).

Outras doenças, como a antracnose, causada por Colletotrichum spp. eas podridóes de Pestalotiopsis, Cladosporium, Phytophthora e Penicillium, ocorreram em menor incidência, inferior a 5\% dos frutos (Fig. 1), não diferindo entre os cultivares (Tabela 2).

Segundo Dik; Wubben (2007), o efeito da adubação nitrogenada na epidemiologia de doenças causadas por Botrytis em tomate, pepino, pimentão, morango, rosa e gérbera, cultivadas em estufa, não foi consistente, entretanto, o incremento de cálcio nos tecidos das plantas geralmente reduziu a suscetibilidade ao patógeno. Aumento na produção e na severidade do mofo cinzento e da antracnose foi observado por WALTER et al., (2008) em morangos submetidos a um incremento na adubaçáo nitrogenada superior ao do presente trabalho, de $250 \%$, sendo menor a intensidade das doenças quando utilizado nitrogênio na forma de nitrato de cálcio, possivelmente em funçâo da maior resistência da planta proporcionada pelo cálcio. Considera-se que o excesso de nitrogênio retarda a maturação de tecidos, tornando-os mais suculentos, aumentando a predisposição do hospedeiro a patógenos. Contudo, a deficiência de nitrogênio afeta o crescimento da planta e a expressão da resistência tanto constitutiva quanto induzida aos patógenos (Dietrich et al., 2004).

Diferenças na incidência de doenças pós-colheita em cultivares de morango têm sido verificadas por outros autores (WANG et al., 2014; Bestfleisch et al., 2015), sendo o cultivar Oso Grande considerado mais resistente ao mofo cinzento (SANTOS, 2005), corroborando os resultados aqui encontrados, entretanto, considerando a não disponibilidade de materiais resistentes às várias doenças importantes, preconiza-se um manejo preventivo no campo, com boas práticas agrícolas, uso adequado de fungicidas e uma adubação equilibrada, e na pós-colheita, boas práticas de manuseio, embalagem e armazenamento refrigerado.

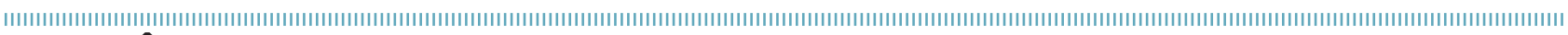
REFERÊNCIAS

BENDO, M.I.; VIECELLI, C.A. Controle biológico de Rhizopus nigricans em pós-colheita de morango pela utilização da levedura Saccharomyces cerevisiae e leite in natura. Cultivando o saber, v.2, n.3, p.23-35, 2009.

BESTFLEISCH, M.; LUDERER-PFLIMPFL, M.; HÖFER, M.; SCHULTE, E.; WÜNSCHE, J.N.; HANKE, M.V.; FLACHOWSKY, H. Evaluation of strawberry (Fragaria L.) genetic resources for resistance to Botrytis cinerea. Plant Pathology, v.64, n.2, p.396-405, 2015.

BRACKMANN, A.; HUNSCHE, M.; WACLAWOVSKI, A.; DONAZZOLO, J. Armazenamento de morangos cv. Oso Grande (Fragaria ananassa L.) sob elevadas pressões parciais de $\mathrm{CO}_{2}$. Revista Brasileira de Agrociência, v.7, n.1, p.10-14, 2001.

CAMARGO, L.K.P.; RESENDE, J.T.V.; GALVÃO, A.G.; CAMARGO, C.K.; BAIER, J.E. Desempenho produtivo e massa média de frutos de morangueiro obtidos de diferentes sistemas de cultivo. Ambiência, v.6, n.2, p.281-288, 2010.
CANTILLANO, R.F.F.; SILVA, M.M. Manuseio pós-colheita de morangos. Embrapa Clima Temperado. Documentos, 318. Pelotas: Embrapa Clima Temperado; 2010. p.36.

DIETRICH, R.; PLOSS, K.; HEIL, M. Constitutive and induced resistance to pathogens in Arabidopsis thaliana depends on nitrogen supply. Plant, Cell and Enviroment, v.27, n.7, p.896-906, 2004.

DIK, A.J.; WUBBEN, J.P. Epidemiology of Botrytis cinerea diseases in greenhouses. In:___. Botrytis: biology, pathology and control. New York: Springer-Verlag; 2007. p.319-333.

HENZ, G.P.; REIS, A.; SILVA, K.C.C.; PEREIRA, S.F. Incidência de doenças de pós-colheita em frutos de morango produzidos no Distrito Federal. Boletim de Pesquisa e Desenvolvimento, 45. Brasília: Embrapa Hortaliças; 2008. 13p.

MARSCHNER, H. Mineral nutrition of higher plants. 2nd ed. San Diego: Academic Press; 1995. 889p. 
PAULL, R.E. Effects of temperature and relative humidity on fresh commodity quality. Postharvest Biology and Technology, v.15, n.3, p.263-277, 1999.

RAIJ, B. VAN. Fertilidade do solo e adubação. São Paulo: Agronômica Ceres; 1991. 343p.

RAIJ, B. VAN.; CANTARELLA, H.; QUAGGIO, J.A.; FURLANI, A.M.C. Recomendações de adubação e calagem para o Estado de São Paulo. Boletim Técnico, 100. 2 ed. Campinas. IAC; 1996.

RIBEIRO, A.C.; GUIMARÃES, P.T.G.; ALVAREZ, V.V.H. Recomendação para o uso de corretivos e fertilizantes em Minas Gerais: $5^{\text {a }}$ aproximação. Viçosa: Comissão de Fertilidade do Solo do Estado de Minas Gerais; 1999. 359p.

SANTOS, P.E.T. Sistema de Produção do Morango: características básicas das principais cultivares de morango plantadas no Brasil.
Embrapa Clima Temperado. Sistemas de Produção, n. 5, 2005. Disponível em: http://sistemasdeproducao.cnptia.embrapa.br/ FontesHTML/Morango/SistemaProducaoMorango/capO2.htm. Acesso em 13 de out. 2015.

TANAKA, M.A.S.; PASSOS, F.A.; FEITOSA, C.T.; TANAKA, R.T. Efeito da adubação mineral e orgânica do morangueiro sobre a antracnose do rizoma, causada por Colletotrichum fragariae. Summa Phytopathologica, v.28, n.3, p.236-241, 2002.

WALTER, M.; BRAITHWAITE, B.; SMITH, B.J.; LANGFORD, G.I. Nutrient nitrogen management for disease control in strawberry. New Zealand Plant Protection, v.61, p.70-79, 2008.

WANG, Y.; CHARLES, M.T.; DONG, W.; DUBÉ, C.; KHANIZADE, S. Distribution of phenolic components and their antioxidant capacity in strawberries. Journal of Food Research, v.3, n.2; p.54-60, 2014. 